\title{
The Influence of a Magnetic Field on the Formation of Corrosion Defects in Selected Metals and Steels, Analysed Using Positron Annihilation Method
}

\author{
R. Pietrzak and R. SzataniK*, \\ Institute of Physics, Opole University, Oleska 48, 45-052 Opole, Poland
}

\begin{abstract}
The method of positron lifetime measurement was used to analyse the influence of a magnetic field on the kinetics of corrosion defect formation in near-surface layers of iron, titanium as well as S20 and S0H18N9 steel grades. The listed metals, which belong to ferro- and paramagnetic materials, have different sensitivity to corrosion. It was found that not only the presence of a magnetic field, but also its direction influence the dimensions and the concentration of defects formed during corrosion.
\end{abstract}

DOI: 10.12693/APhysPolA.125.733

PACS: 78.70.Bj, 61.72.Cc, 82.45.Bb

\section{Introduction}

Corrosion is a physical and chemical phenomenon always connected with the formation and movement of defects in near-surface layers of the corroding material. The last dozen of years has also seen the use of methods known from nuclear physics, particularly those based on positron annihilation. Publications [1-9] demonstrate that measurements of positron lifetimes in metals with corroded surfaces provide valuable information about early stages of corrosion defect formation, whose stages usually cannot be studied using other physical or chemical methods. Positrons emitted from $\beta^{r}$ radioactive sources (e.g., ${ }^{22} \mathrm{Na}$ ) with a continuous energy spectrum penetrate the near-surface areas of metals down to the depth of several dozen micrometres (e.g., down to the depth of $41 \mu \mathrm{m}$ in $\mathrm{Ti}$ and $29 \mu \mathrm{m}$ in iron [10]). In order to develop effective methods of preventing corrosion, one must fully understand the impact of various external factors on this phenomenon, such as a magnetic field. The results of experimental research are also ambiguous in this regard. In some metals (e.g., iron and copper), a magnetic field inhibits corrosion in some conditions, but in other metals (Ti), the field accelerates it. Kelly [11] found that an external magnetic field accelerates corrosion processes in ferromagnetic iron and steel, but has no visible impact on corrosion in austenitic steel. Linhardt and co-workers [12] demonstrated that as long as the metal is passive, the magnetic field has no impact on the kinetics of corrosion pit formation in AISI 304 austenitic steel. In publications $[8,9]$, we have demonstrated that the changes in the intensity of the defect component of positron lifetime spectra for iron and S20 steel are clearly smaller if the samples were "aged" in an external magnetic field before corroding. This can be due to the following changes:

*corresponding author; e-mail: szata@uni.opole.pl a) in the energetic structure of magnetic domains, or

b) in the structure of the passive layer on the surface of metal.

From the physical point of view, the passive layer can be treated as a membrane conducting ions and defects, inside which there is a strong electrical field.

\section{Preparation of samples for research}

Positron annihilation was studied in $99.99 \%$ pure $\mathrm{Fe}$ and Ti samples, as well as in steel grades of the percentage compositions presented in Table I. The samples were cylindrical with $10 \mathrm{~mm}$ in diameter and thickness of $2 \mathrm{~mm}$. In order to eliminate above-equilibrium defects all samples were annealed for $3 \mathrm{~h}$ in vacuum $\left(p<10^{-3}\right.$ mbar) at temperatures: $850^{\circ} \mathrm{C}$ for $\mathrm{Fe}, 500^{\circ} \mathrm{C}$ and $1100^{\circ} \mathrm{C}$ for $\mathrm{Ti}$, and $500^{\circ} \mathrm{C}$ for both steel grades and slowly cooled at the rate of $1^{\circ} \mathrm{C} / \mathrm{min}$ to room temperature. Then for the annealed samples positron lifetimes were measured.

TABLE I

Percentage compositions of the investigated steel grades.

\begin{tabular}{c|c|c|c|c|c|c|c|c|c|c}
\hline \hline & $\mathrm{C}$ & $\mathrm{Si}$ & $\mathrm{Mn}$ & $\mathrm{P}$ & $\mathrm{S}$ & $\mathrm{Cr}$ & $\mathrm{Ni}$ & $\mathrm{Mo}$ & $\mathrm{Cu}$ & $\mathrm{V}$ \\
\hline S20 & 0.22 & - & 1.1 & - & - & - & - & - & - & - \\
S0H18N9 & 0.012 & 0.29 & 1.13 & 0.028 & 0.026 & 18.37 & 8.12 & 0.36 & 0.35 & 0.09
\end{tabular}

For further annihilation research, samples were prepared as follows: selected samples were magnetically aged, placed between the poles of a magnet for $150 \mathrm{~h}$ perpendicular or parallel to the magnetic induction vector. The magnetic field had the induction of $B=276 \mathrm{mT}$. Next, the samples, appropriately oriented relative to the magnetic field, were placed in a plexiglass container above the surface of a $3 \%$ water $\mathrm{HCl}$ solution, where they corroded for $150 \mathrm{~h}$ in the vapour from this solution (Fig. 1). Some samples were subjected to corrosion directly after annealing, without being held in a magnetic field.

Positron lifetime spectra were measured using a FastFast spectrometer with the resolution of $275 \mathrm{ps}$ and spectrum parameters were calculated using the Lifetime 9 computer programme. 


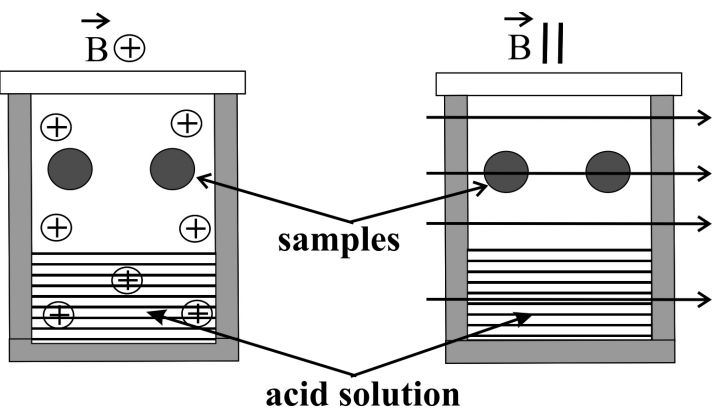

Fig. 1. Orientation of samples in a magnetic field: perpendicular $\oplus$ or parallel $\|$ to the surface of the sample.

\section{Results and interpretation}

This publication presents the results of analysing positron lifetime in ferro- and paramagnetic metals (Fe, Ti, S20, and S0H18N9 steel grades). Fe and S20 steel are ferromagnetic and susceptible to pit corrosion, while Ti and S0H18N9 steel are paramagnetic and resistant to corrosion.

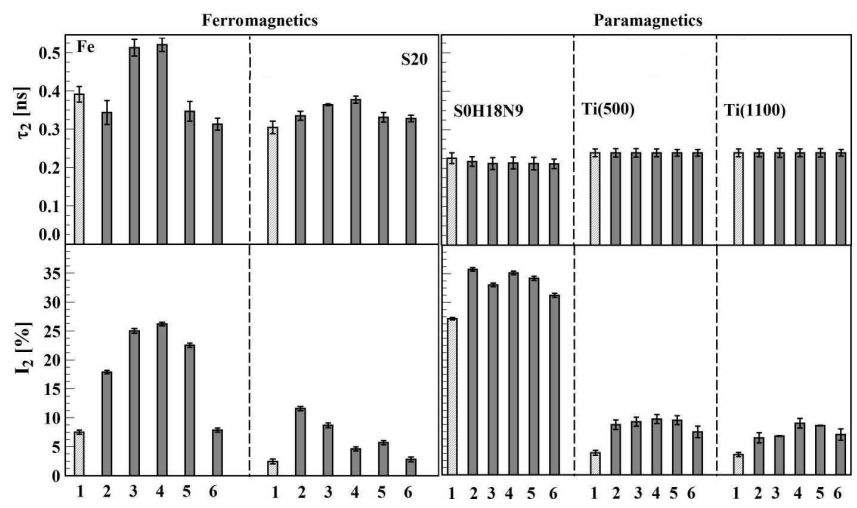

Fig. 2. Diagrams of lifetimes $\left(\tau_{2}\right)$ and intensities $\left(I_{2}\right)$ of the second component of positron lifetime spectra in $\mathrm{Fe}, \mathrm{S} 20$, and S0H18N9 steel grades, as well as Ti before corrosion and after corrosion in a magnetic field (the marking of the samples is to be found in the text).

Figure 2 shows diagrams $\tau_{2}$ and $I_{2}$ of the second component of positron lifetime spectra for samples marked further in the text as follows: (1) before corrosion, (2) corroding outside the magnetic field, directly after annealing, (3) corroding in a perpendicular magnetic field directly after annealing, (4) corroding after "magnetic aging" in a perpendicular magnetic field, (5) corroding in a parallel magnetic field directly after annealing, (6) corroding after "magnetic aging" in a parallel magnetic field, $\mathrm{Ti}(500)$ - titanium samples annealed at $500^{\circ} \mathrm{C}, \mathrm{Ti}(1100)$ - titanium samples annealed at $1100{ }^{\circ} \mathrm{C}$.

Numerical values of $\tau_{2}$ indicate that in iron and steel positrons annihilate in multi-vacancy clusters, while in titanium in vacancies [13-15]. In all cases, the intensities of this component are clearly greater after corrosion than before it. However, the lifetime of positrons depends on the direction of the external magnetic field in which cor- rosion occurred. It can be simplistically assumed that in the ferromagnetics for samples (2) the values of $\tau_{2}$ remain - within the limits of error - unchanged. On the other hand, for samples (3) and (5) these values vary. In titanium (a paramagnetic), magnetic conditions do not influence the values of lifetime $\tau_{2}$. Relative changes of intensities of this component are greater in ferromagnetic materials than in paramagnetic metals.

Based on the multi-state annihilation model [16], it can be assumed that in the analysed ferromagnetics, after magnetic aging, conditions arise for the creation of above-equilibrium defects which easily form multi-vacancy clusters. In paramagnetic austenitic steel, the size of vacancy clusters remains unchanged, within the limits of error. An analysis of changes in the value of $\tau_{2}$ for titanium suggests that above-equilibrium vacancies are produced in the corrosion process. Their concentration depends not only on the direction of the magnetic field penetrating the sample during its corrosion, but also on whether the corrosion occurs directly after annealing, or after a previous aging in a magnetic field. This result proves that in the corrosion process of titanium, the structure of the passive layer on grain surfaces plays a huge role in the formation and migration of vacancies. Assuming that titanium samples previously annealed at various temperatures differ in the morphology of the passive layer, positron annihilation was analysed in corroded $\operatorname{Ti}(500)$ and $\operatorname{Ti}(1100)$ samples. The intensity $I_{2}$ of the defect component is usually smaller in $\mathrm{Ti}(1100)$ samples than in $\mathrm{Ti}(500)$. This proves the greater uniformity of the passive layer which, as a result of the action of forces of an electromagnetic origin, is more defective and deformed in a parallel field than in a perpendicular one.

Table II shows the relative changes of the $\tau_{2}$ and $I_{2}$ parameters calculated as the difference between the parameters $(P)$ after the corrosion (a) and before the corrosion (b) relative to the parameters prior to the corrosion

$$
\frac{\Delta P}{P}=\frac{P_{\mathrm{a}}-P_{\mathrm{b}}}{P_{\mathrm{b}}},
$$

where $P=\tau_{2}, I_{2}$. For samples (4) and (6), as the values of $P_{\mathrm{b}}$, we accepted those that were designated after magneting aging, but before corrosion.

It was noted that the relative change in annihilation parameters depends on whether corrosion occurred for samples (3) and (5) or for samples (4) and (6).

Obviously, changes of $I_{2}$ for samples (4) and (6) are generally smaller than for samples (2), (3) and (5). Similarly, the changes of this parameter for samples (5) are smaller than for samples (3). These results suggest that not only the temperature at which the passive layer forms before the corrosion, but also the direction of the magnetic field in which this layer forms may impact the annihilation parameters of the original sample. To check this hypothesis, first the positron lifetime spectra were measured in samples directly after their annealing, and then after their aging in a magnetic field, without a corrosive atmosphere. 
TABLE II

Relative changes of parameters of positron lifetime spectra for "direct" corrosion and corrosion after "magnetic aging".

\begin{tabular}{|c|c|c|c|c|c|}
\hline \multirow[t]{2}{*}{ Metal } & \multirow{2}{*}{$\begin{array}{l}\text { Orientation of samples } \\
\text { in a magnetic field }\end{array}$} & \multicolumn{2}{|c|}{ "Direct" corrosion } & \multicolumn{2}{|c|}{$\begin{array}{l}\text { Corrosion after } \\
\text { "magnetic aging" }\end{array}$} \\
\hline & & $\Delta \tau_{2} / \tau_{2}[\%]$ & $\Delta I_{2} / I_{2}[\%]$ & $\Delta \tau_{2} / \tau_{2}[\%]$ & $\Delta I_{2} / I_{2}[\%]$ \\
\hline \multirow{3}{*}{$\mathrm{Fe}$} & $B=0$ & $-2.27 \pm 0.35$ & $138.67 \pm 8.73$ & - & - \\
\hline & $\oplus$ & $45.76 \pm 7.41$ & $234.00 \pm 12.48$ & $1.60 \pm 0.34$ & $89.72 \pm 2.16$ \\
\hline & $\|$ & $-1.42 \pm 1.85$ & $200.93 \pm 11.65$ & $-2.72 \pm 0.78$ & $-48.80 \pm 1.00$ \\
\hline \multirow{3}{*}{$\mathrm{S} 20$} & $B=0$ & $9.86 \pm 1.83$ & $364.00 \pm 58.24$ & - & - \\
\hline & $\oplus$ & $19.30 \pm 5.43$ & $249.20 \pm 39.87$ & $5.47 \pm 1.69$ & $63.03 \pm 2.06$ \\
\hline & $\|$ & $8.68 \pm 1.76$ & $128.40 \pm 22.14$ & $-1.20 \pm 0.06$ & $-12.58 \pm 4.11$ \\
\hline \multirow{3}{*}{ S0H18N9 } & $B=0$ & $-12.45 \pm 0.10$ & $40.39 \pm 0.03$ & - & - \\
\hline & $\oplus$ & $-14.86 \pm 4.14$ & $29.80 \pm 0.05$ & $0.75 \pm 0.6$ & $16.81 \pm 0.25$ \\
\hline & $\|$ & $-14.70 \pm 1.63$ & $34.24 \pm 0.16$ & $-0.33 \pm 0.13$ & $-8.86 \pm 0.13$ \\
\hline \multirow{3}{*}{$\operatorname{Ti}(500)$} & $B=0$ & 0.00 & $126.73 \pm 5.44$ & - & - \\
\hline & $\oplus$ & 0.00 & $163.63 \pm 13.61$ & 0.00 & $109.91 \pm 0.23$ \\
\hline & $\|$ & 0.00 & $169.89 \pm 13.07$ & 0.00 & $9.97 \pm 0.96$ \\
\hline \multirow{3}{*}{$\operatorname{Ti}(1100)$} & $B=0$ & 0.00 & 0.00 & & \\
\hline & $\oplus$ & 0.00 & $76.10 \pm 16.89$ & 0.00 & $190.16 \pm 59.28$ \\
\hline & $\|$ & 0.00 & $122.34 \pm 21.65$ & 0.00 & $2.93 \pm 1.83$ \\
\hline
\end{tabular}

Figure 3 shows relative changes of parameters of the defect component of the positron lifetime spectrum in the investigated metals caused by aging in a magnetic field of the appropriate orientation. It can be seen that for all analysed metals except $\mathrm{Ti}(1100)$, samples aging in a magnetic field causes the intensities of this component to increase $\left(\frac{\Delta I_{2}}{I_{2}}>0\right)$.

This can be interpreted as a result of an increased concentration of defects in near-surface layers penetrated by positrons. The increases in their concentration are greater when metals age in a field parallel to sample surface than if they age in a perpendicular field. We believe that this results from the additional damaging and stressing of the passive layer which can be treated as a material conducting the electrical current of ions and vacancies, placed in a magnetic field. Hence, it can be claimed that the passive layer is more sensitive to formation of larger defects in ferromagnetic materials than in paramagnetic ones. The formed passive layer in the paramagnetic materials is cohesive and more resistant to formation of vacancies.

\section{Conclusions}

The obtained results of the positron lifetime measurements demonstrate that in the near-surface layers of $\mathrm{Fe}$, $\mathrm{Ti}$, as well as S20, and S0H18N9 steel grades additional defects form as a result of corrosion. Corrosion in the presence of a magnetic field causes formation of defect clusters in iron and the steel grades, but in titanium only increase of vacancy concentrations. The orientation of the external magnetic field relative to the corroding surface of samples influences the concentration of defects produced in the near-surface layer of metal.

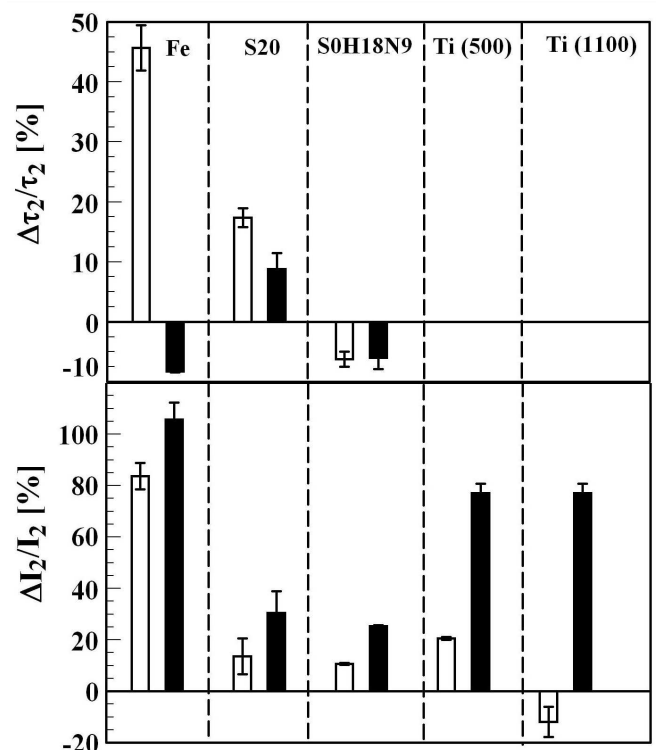

Fig. 3. A diagram of relative changes in the lifetimes $\left(\Delta \tau_{2} / \tau_{2}\right)$ and intensities $\left(\Delta I_{2} / I_{2}\right)$ in Fe, S20, and S0H18N9 steel grades and Ti caused by "aging" in a magnetic field perpendicular ( $\square$ ) and parallel (口) to the surface of the sample without a corrosive atmosphere.

\section{References}

[1] R. Pietrzak, R. Szatanik, M. Szuszkiewicz, Acta Phys. Pol. A 95, 647 (1999).

[2] R. Pietrzak, W. Smiatek, R. Szatanik, M. Szuszkiewicz, Fract. Mech. Mater. Mater. Integr. 2, 178 (1999). 
[3] R. Pietrzak, R. Szatanik, W. Smiatek, M. Szuszkiewicz, in: Proc. 31st Seminar on Positron Annihilation, Jarnołtówek (Poland), 1999, Eds.: W. Świątkowski, K. Jerie, Opole University, Opole 2000, p. 123.

[4] R. Pietrzak, R. Szatanik, W. Smiatek, in: Proc. 33rd Polish Seminar on Positron Annihilation, Turawa (Poland), 2001, Ed.: K. Jerie, Opole University, Opole 2001, p. 79.

[5] R. Pietrzak, in: Proc. 34th Polish Seminar on Positron Annihilation, Turawa (Poland), 2002, Ed.: K. Jerie, Opole University, Opole 2002, p. 67.

[6] R. Pietrzak, R. Szatanik, A. Jaworska, Acta Phys. Pol. A 110, 677 (2006).

[7] R. Pietrzak, W. Smiatek, R. Szatanik, Acta Phys. Pol. A 110, 667 (2006)

[8] R. Pietrzak, R. Szatanik, Nukleonika 55, 31 (2010).
[9] R. Pietrzak, R. Szatanik, Phys. Status Solidi B 247, 1822 (2010).

[10] J. Dryzek, Acta Phys. Pol. A 107, 598 (2005).

[11] E.J. Kelly, J. Electrochem. Soc. 124, 987 (1977).

[12] P. Linhardt, G. Ball, E. Schlemmer, Corr. Sci. 47. 1599 (2005).

[13] H.E. Schaefer, Phys. Status Solidi A 102, 47 (1987).

[14] K. Zaleski, W. Gustaw, A. Parol, T. Goworek, in: Proc. Scientific/Technical Conf. Producing Machine Parts of Metal Alloys of Special Properties, Rzeszów (Poland), Ed.: J. Łunarski, Rzeszów 1985, p. 270.

[15] K. Zaleski, R. Zaleski, Mater. Eng. 5, 302 (2009).

[16] P. Hautojärvi, Positron in Solids, Springer-Verlag, Berlin 1979. 